\title{
Colonic stent versus emergency surgery as treatment of malignant colonic obstruction in the palliative setting: a systematic review and meta-analysis
}

\section{다 (1) $(2)$}

\section{Authors}

Igor Braga Ribeiro', Wanderley Marques Bernardo², Bruno da Costa Martins ${ }^{1}$, Diogo Turiani Hourneaux de Moura1, Elisa Ryoka Baba ${ }^{1}$, latagan Rocha Josino ${ }^{1}$, Nelson Tomio Miyajima ${ }^{1}$, Martin Andrés Coronel Cordero', Thiago Arantes de Carvalho Visconti ${ }^{1}$, Edson Ide ${ }^{1}$, Paulo Sakai ${ }^{1}$, Eduardo Guimarães Hourneaux de Moura ${ }^{1}$

Institutions

1 Hospital das Clínicas da Faculdade de Medicina da Universidade de São Paulo - HC/FMUSP, Gastrointestinal Endoscopy Unit, São Paulo, Brazil

2 Hospital das Clínicas da Faculdade de Medicina da Universidade de São Paulo - HC/FMUSP, Thoracic Surgery Department, São Paulo, Brazil

submitted 10.1.2018

accepted after revision $\quad 12.2 .2018$

\section{Bibliography}

DOI https://doi.org/10.1055/a-0591-2883 |

Endoscopy International Open 2018; 06: E558-E567

(c) Georg Thieme Verlag KG Stuttgart · New York

ISSN 2364-3722

Corresponding author

Igor Braga Ribeiro, MD, Av. Dr. Enéas de Carvalho Aguiar

255, Instituto Central, Prédio dos Ambulatórios, Pinheiros, CEP: 05403-000, São Paulo, Brazil

Fax: +551130697579

igorbraga1@gmail.com

\section{ABSTRACT}

Background and study aims Colorectal cancer (CRC) is the third most common malignancy and the third leading cause of cancer death worldwide. Malignant colonic obstruction (MCO) due to CRC occurs in $8 \%$ to $29 \%$ of patients. The aim of this study was to perform a systematic review and meta-analysis of RCTs comparing colonic SEMS versus emergency surgery (ES) for MCO in palliative patients. This was the first systematic review that included only randomized controlled trials in the palliative setting.
Methods A literature search was performed according to the PRISMA method using online databases with no restriction regarding idiom or year of publication. Data were extracted by two authors according to a predefined data extraction form. Primary outcomes were: mean survival, 30day adverse events, 30-day mortality and length of hospital stay. Stoma formation, length of stay on intensive care unit (ICU), technical success and clinical success were recorded for secondary outcomes. Technical success (TS) was defined as successful stent placement across the stricture and its deployment. Clinical success (CS) was defined as adequate bowel decompression within $48 \mathrm{~h}$ of stent insertion without need for re-intervention.

Results We analyzed data from four RCT studies totaling 125 patients. The 30 -day mortality was $6.3 \%$ for SEMStreated patients and $6.4 \%$ for ES-treated patients, with no difference between groups (RD: $-0.00,95 \% \mathrm{Cl}[-0.10$, $0.10], I^{2}$ : $\left.0 \%\right)$. Mean survival was 279 days for SEMS and 244 days for $E S$, with no significant difference between groups (RD: $20.14,95 \% \mathrm{Cl}$ : [-42.92, 83.21], I²: 44\%). Clinical success was $96 \%$ in the ES group and $86.1 \%$ in the SEMS group (RD: $-0.13,95 \% \mathrm{Cl}[-0.23,-0.02], \mathrm{I}^{2}$ : $51 \%$ ). Permanent stoma rate was $84 \%$ in the ES group and $14.3 \%$ in the SEMS group (RR: $0.19,95 \% \mathrm{Cl}$ : [0.11, 0.33], I2: $28 \%$ ). Length of hospital stay was shorter in SEMS group (RD: - 5.16, $95 \%$ $\mathrm{Cl}$ : [-6.71,-3.61], I2: 56\%). There was no significant difference between groups regarding adverse events (RD 0.18, $95 \% \mathrm{Cl}:[-0.19,0.54 ;])$ neither regarding ICU stay. (RD: $\left.-0.01,95 \% \mathrm{Cl}:[-0.08,0.05], \mathrm{I}^{2}: 7 \%\right)$. The most common stent-related complication was perforation $(42.8 \%$ of all AE).

Conclusion Mortality, mean survival, length of stay in the ICU and early complications of both methods were similar. SEMS may be an alternative to surgery with the advantage of early hospital discharge and lower risk of permanent stoma. 


\section{Introduction}

Colorectal cancer (CRC) is the third most common malignancy and the third leading cause of cancer death worldwide. Malignant colonic obstruction (MCO) due to CRC occurs in $8 \%$ to $29 \%$ of patients, which is a gastrointestinal emergency requiring urgent decompression. If not adequately treated, MCO can lead to electrolytic fluid imbalance, bacterial translocation, colonic necrosis, and death [1-3].

Surgery has been the primary treatment of MCO for decades although surgical morbidity and mortality are higher in emergency scenarios than in elective procedures [4-6]. In the mid1990 s, endoscopic self-expanding metal stents (SEMS) emerged as a treatment for gastrointestinal surgical emergencies [7 -9], including MCO, and the first studies raised high expectations because use of stents could avoid surgical intervention such as colostomy, leading to reduced morbidity and mortality, possibly resulting in higher quality of life (QOL) [10-11].

Many studies, including 13 randomized controlled trials (RCTs) [12-24] and 20 meta-analyses, have reported results of colonic SEMS as a bridge to surgery. However, SEMS use with palliative intent is not well studied.

The aim of this study was to perform a systematic review and meta-analysis of RCTs comparing colonic SEMS versus emergency surgery (ES) for MCO in palliative patients. This was the first systematic review that included only RCTs in the palliative setting.

\section{Methods}

\section{Protocol and registration}

A protocol was established and documented prior to initiating the study to specify eligibility criteria and analytical methods for the studies included in this systematic review and meta-analysis. This protocol can be accessed at http://www.crd.york. ac.uk/PROSPERO/display_record.php?ID=CRD42017082304

\section{Study selection}

A literature search was performed using MEDLINE, EMBASE, the Cochrane Library, Scopus, LILACS, BVS, Cochrane Central Register of Controlled Trials (CENTRAL), and The Cumulative Index to Nursing and Allied Health Literature (CINAHL) databases from March 2017 to November 2017, with no restriction regarding the idiom or the year of publication. The search results are shown in the supplementary material.

Complete manuscripts of all relevant studies published were retrieved, and reference lists were searched to identify any additional relevant papers. When more than one publication by the same group of investigators was available, the latest and most complete study was included in the analysis.

Reviews, meta-analysis, letters, editorials, abstracts, unpublished studies, case reports, and small case series were excluded.

\section{Inclusion criteria}

RCTs comparing colonic SEMS versus surgery for malignant large bowel obstruction in palliative patients were included.

\section{Exclusion criteria}

Studies reporting the following were excluded: stenting for benign stenosis; stents as a bridge to surgery; stents placed under fluoroscopic guidance alone by an interventional radiologist; inadequate data on outcome variables for the two techniques; and reports wherein the data were impossible to calculate from the published results.

\section{Data extraction}

Data were extracted by two authors (IB and BM) according to a predefined data extraction form. Disagreements were resolved by consulting with a third investigator.

Data regarding study characteristics, total number of patients included, characteristics of the study population, and the number of subjects in each group were collected. Clinical variables included the American Society of Anesthesiologists classification (ASA), tumor site, metastasis, the type of stent used, and technical and clinical success after stent placement.

Technical success (TS) was defined as successful stent placement across the stricture and its deployment. Clinical success (CS) was defined as adequate bowel decompression within 48 hours of stent insertion without the need for reintervention.

Primary outcomes included 30-day mortality, survival, CS, and early adverse events (from 0 to 30 days). Secondary outcomes included TS, stoma formation, intensive care unit (ICU) stay, and length of hospital stay.

\section{Assessment of study quality}

Four RCTs were included in the analysis. The quality of these studies was assessed by appliying the Jadad score and the Cochrane Collaboration's tool for assessing risk of bias ( $\triangleright$ Table 1 ).

\section{Statistical analysis}

Regarding meta-analysis, the difference was calculated as the risk difference (RD) for the Cochran-Mantel-Haenszel test with a $95 \%$ confidence interval $(\mathrm{Cl})$ dichotomous variables and as the mean difference (MD) with fixed effect using inverse variance with a $95 \% \mathrm{Cl}$ for continuous variables. Semi-quantitative measures were described as arithmetic mean, standard deviation (SD), and results of Student's t-test analysis. All data were addressed in an intention-to-treat (ITT) analysis.

The RevMan 5 software (Review Manager Version 5.3.5: Cochrane Collaboration, Copyright (c) 2014) was used for the meta-analysis of primary and secondary outcomes. Student's $t$-test was used to compare the weighted arithmetic means survival, time stay on the ICU and hospital stay because the standard deviation of these data could not be extracted from most of the included studies. Heterogeneity was tested with the Q test for significance and with the inconsistency index $\left(I^{2}\right)$, where a value $>50 \%$ was considered as substantial heterogeneity between studies. A funnel plot was generated and linear regression tests were performed excluding the studies that were loca- 
- Table 1 Methods used in therapeutic studies.

\begin{tabular}{|c|c|c|c|c|c|c|c|c|c|c|}
\hline Study & $\begin{array}{l}\text { Clinical } \\
\text { question }\end{array}$ & $\begin{array}{l}\text { Adequacy ran- } \\
\text { domization }\end{array}$ & $\begin{array}{l}\text { Allocation } \\
\text { concealment }\end{array}$ & $\begin{array}{l}\text { Double- } \\
\text { blinding }\end{array}$ & $\begin{array}{l}\text { Dropouts } \\
(<20 \%)\end{array}$ & $\begin{array}{l}\text { Characteristics, } \\
\text { prognostics or } \\
\text { demographic }\end{array}$ & Outcomes & $\begin{array}{l}\text { Intent- } \\
\text { to- } \\
\text { treat }\end{array}$ & $\begin{array}{l}\text { Sample } \\
\text { size }\end{array}$ & Jadad \\
\hline $\begin{array}{l}\text { Young, } 2015 \\
\text { [10] }\end{array}$ & Yes & Yes & Yes & No & Yes & No & Yes & Yes & Yes & 4 \\
\hline $\begin{array}{l}\text { Fiori, } 2012 \\
{[25]}\end{array}$ & Yes & Yes & Yes & No & Yes & Yes & Yes & Yes & No & 3 \\
\hline $\begin{array}{l}\text { Van Hooft, } \\
2008 \text { [26] }\end{array}$ & Yes & Yes & Yes & No & Yes & No & Yes & Yes & Yes & 3 \\
\hline $\begin{array}{l}\text { Xinopoulos, } \\
2004 \text { [28] }\end{array}$ & Yes & $\mathrm{Nr}$ & $\mathrm{Nr}$ & Yes & Yes & No & Yes & Yes & No & 3 \\
\hline
\end{tabular}

ted outside the funnel plot (outliers). Next, another meta-analysis was performed without the outliers. True heterogeneity was presumed and the random effects model was applied in case of persistent high heterogeneity or if outliers could not be detected.

\section{Results}

A search of the literature yielded 32,048 records from all databases. In total, 27 trials were included in the initial selection of articles on surgery and stents; four studies were duplicates. Therefore, full texts of 23 studies were reviewed and 19 were excluded for one or more of the following reasons: the study was not a controlled clinical trial; SEMS was used as a bridge to elective surgery; or the study was irrelevant to this topic.

Finally, four RCTs were selected for this study including 125 patients ( $\triangleright$ Fig. 1 ).

\section{Results of individual studies}

Characteristics and available data on the number of patients in each group, their ages, the location of neoplasia (i.e., colonic or rectal), metastasis, and ASA status for all included studies are summarized in $>$ Table 2.

\section{Primary outcomes}

Mortality rate was assessed in all of the included studies. Thirty-day mortality was $6.3 \%$ in the SEMS group and $6.4 \%$ in the ES group, but mortality rate did not statistically differ between the groups (RD: $0.00,95 \% \mathrm{Cl}:-0.10-+0.10 \mathrm{I}^{2}$ : 0\%). Egger's linear regression test did not reveal any publication bias (bias $=0.03$; $P=0.98$ ) ( Fig. 2). In three studies assessing survival, mean survival was 279 days in the SEMS group and 244 days in the ES group, with no statistically significant difference between groups (MD: $20.14,95 \% \mathrm{Cl}:-42.92$ to $+83.21, \mathrm{I}^{2}$ : $44 \%$ ) ( $\triangleright$ Fig. 3). CS was higher in the ES group (96\%) than in the SEMS group (84\%) (RD: $-0.13,95 \% \mathrm{Cl}:-0.23$ to $-0.02, \mathrm{I}^{2}$ : $51 \%$ ) ( $>$ Fig.4). Data regarding 30-day adverse events (AEs) were available for all four studies, with no statistically significant difference between the groups regarding AEs (RD: $0.18,95 \% \mathrm{Cl}$ : -0.19 to $+0.54, \mathrm{I}^{2}: 87 \%$ ) ( Fig. 5).
Potentially relevant studies identified and screened for retrieval $(n=32,048)$

\section{Non-RCTs $(n=29,201)$}

Potentially relevant studies identified and screened for retrieval $(n=2,847)$

Non-RCTs comparing stent vs. surgery $(n=2,820)$

RCTs retrieved for more detailed evaluation $(n=27)$

Systematic reviews and meta-analyses $(n=10)$

Potentially appropriate RCTs ( $\mathrm{n}=17$ )

RCTs on "bridge to surgery" or comparing two types of SEMS $(n=13)$

RCTs with usable information by outcomes $(n=4)$

- Fig. 1 Search strategy [36].

\section{Secondary outcomes}

TS was compared using ITT analysis, slightly favoring the ES group (RD: -0.13 , $95 \% \mathrm{Cl}$ : -0.23 to $-0.02 \mathrm{I}^{2}$ : $51 \%$ ) (ฉ Fig. 6).

Stoma formation was higher in the ES group, in which $86.1 \%$ of the patients underwent a definitive colostomy compared to $14.3 \%$ of patients in the SEMS group (RR: $0.19,95 \% \mathrm{Cl}: 0.11-$ $0.33, \mathrm{I}^{2}: 28 \%$ ) ( Fig. 7). Three studies reported ICU admission after treatment and corresponding information from the fourth article was acquired from the author [25]. Meta-analysis revealed no statistically significant difference between the groups (MD: $-0.01,95 \% \mathrm{Cl}:-0.08$ to $+0.05, \mathrm{I}^{2}:$ \% \%) (> Fig. 8). All studies reported the length of hospital stay ( $>$ Fig.9). In case of high heterogeneity ( $\mathrm{I}^{2}: 74 \%$ ), funnel plot ( $\mathbf{F i g . 1 0}$ ) analysis was performed to detect an outlier study [26], and heterogeneity decreased after removal of that study (I2: $56 \%$ ) ( $\triangleright$ Fig. 11). Mean hospital stay was 17.5 days in the SEMS group 


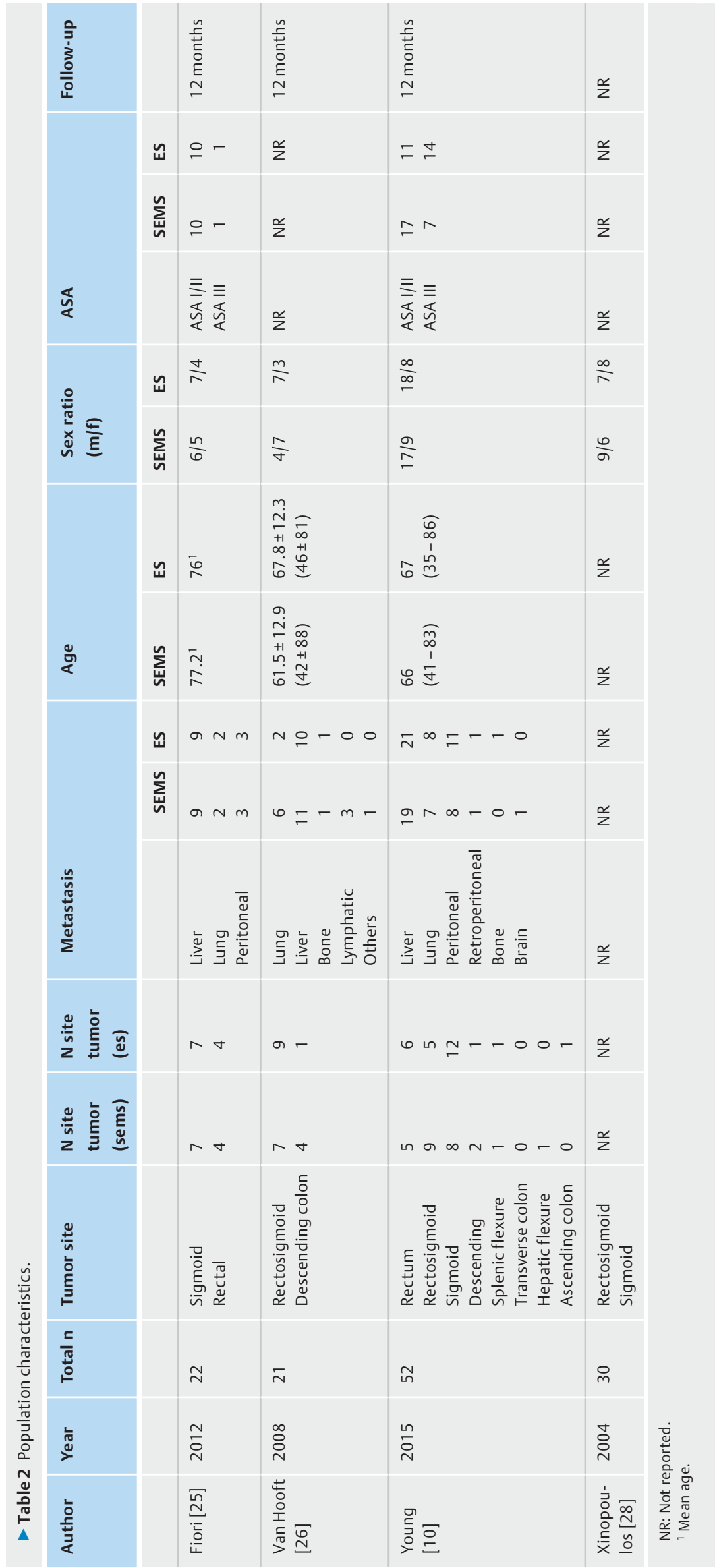




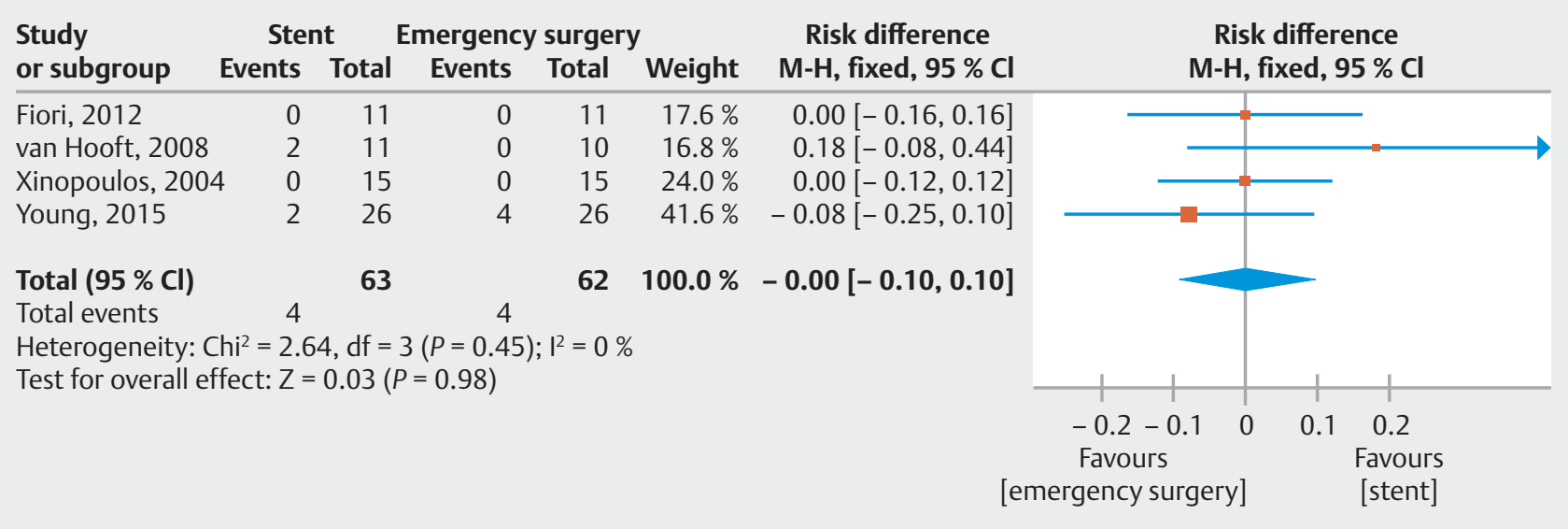

Fig. 2 Mortality in 30 days.

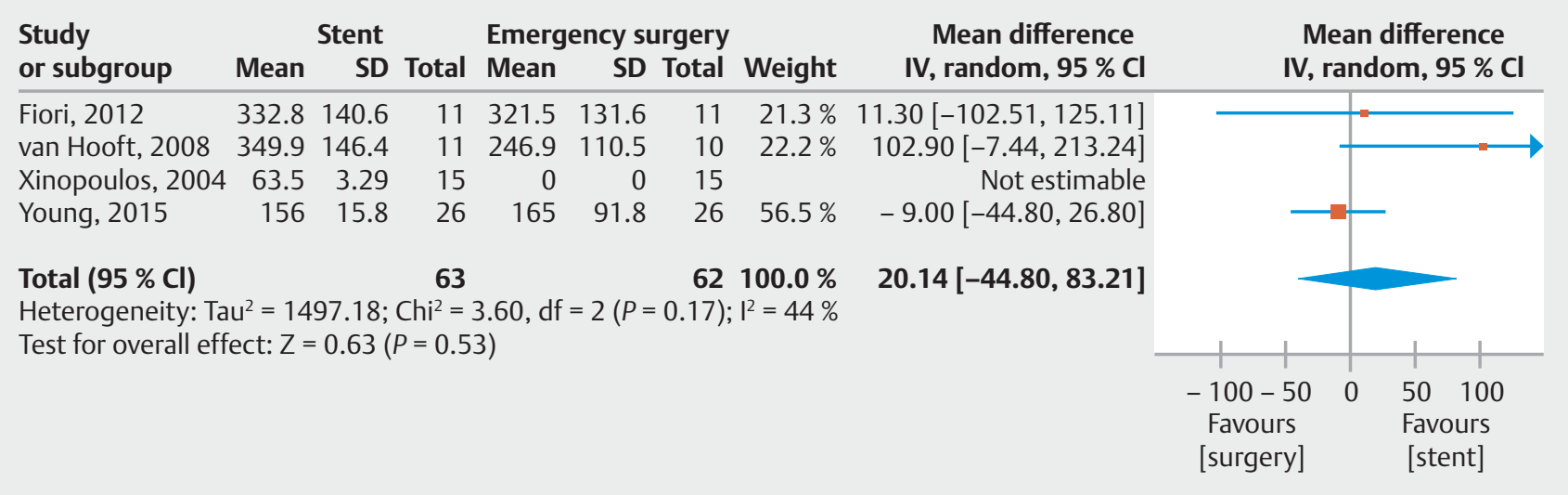

Fig. 3 Survival.

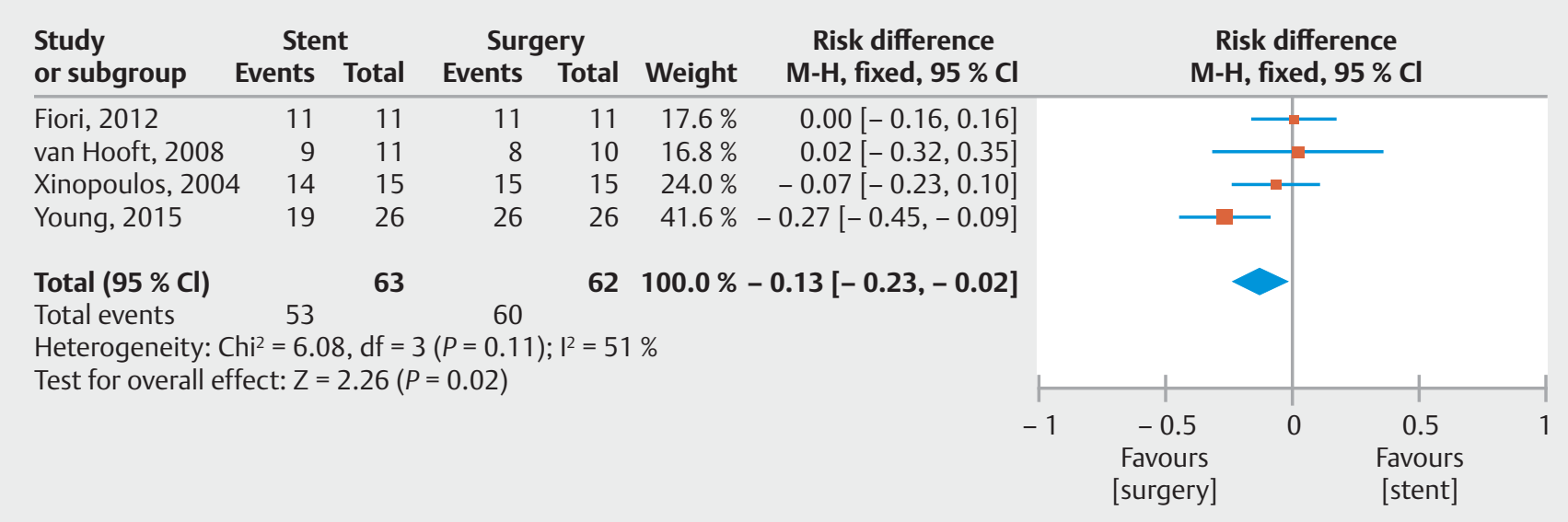

- Fig. 4 Clinical success. 


\begin{tabular}{|c|c|c|c|c|c|c|}
\hline \multirow{2}{*}{$\begin{array}{l}\text { Study } \\
\text { or subgroup }\end{array}$} & \multicolumn{2}{|c|}{ Stent } & \multicolumn{2}{|c|}{ Surgery } & \multirow{2}{*}{ Weight } & \multirow{2}{*}{$\begin{array}{c}\text { Risk difference } \\
\mathrm{H}, \text { random, } 95 \% \mathrm{Cl}\end{array}$} \\
\hline & Events & Total & Events & Total & & \\
\hline Fiori, 2012 & 0 & 11 & 1 & 11 & $26.0 \%$ & $-0.09[-0.31,0.13]$ \\
\hline van 1 & 4 & 11 & 0 & 10 & & 0.3 \\
\hline Xinopoulos, 2004 & 9 & 15 & 0 & 15 & & .86 \\
\hline Young, 2015 & 10 & 26 & 14 & 26 & $24.8 \%$ & $-0.15[-0.42$ \\
\hline & & & & 62 & & \\
\hline Total events & 23 & & 15 & & & \\
\hline
\end{tabular}

Heterogeneity: Tau $^{2}=0.12 ; \mathrm{Chi}^{2}=23.64, \mathrm{df}=3(P<0.0001) ; \mathrm{I}^{2}=87 \%$

Test for overall effect: $Z=0.95(P=0.34)$

- Fig. 5 Early adverse events (30 days).

\begin{tabular}{|c|c|c|c|c|c|c|c|c|c|}
\hline $\begin{array}{l}\text { Study } \\
\text { or subgroup }\end{array}$ & \multicolumn{2}{|c|}{ Stent } & \multicolumn{2}{|c|}{ Emergency surger } & Weight & $\begin{array}{c}\text { Risk difference } \\
\text { M-H, fixed, } 95 \% \mathrm{Cl}\end{array}$ & \multicolumn{3}{|c|}{$\begin{array}{c}\text { Risk difference } \\
\text { M-H, fixed, } 95 \% \mathrm{Cl}\end{array}$} \\
\hline Fiori, 2012 & 11 & 11 & 11 & 11 & $17.6 \%$ & $0.00[-0.16,0.16]$ & $\longrightarrow$ & -1 & \\
\hline van Hooft, 2008 & 9 & 11 & 8 & 10 & $16.8 \%$ & $0.02[-0.32,0.35]$ & & & \\
\hline Xinopoulos, 2004 & 14 & 15 & 15 & 15 & $24.0 \%$ & $-0.07[-0.23,0.10]$ & $\longrightarrow$ & — & \\
\hline Young, 2015 & 19 & 26 & 26 & 26 & $41.6 \%$ & $-0.27[-0.45,-0.09]$ & $\longrightarrow$ & & \\
\hline \multirow{2}{*}{$\begin{array}{l}\text { Total }(95 \% \text { Cl) } \\
\text { Total events }\end{array}$} & & 63 & & 62 & $100.0 \%$ & $-0.13[-0.23,-0.02]$ & & & \\
\hline & 53 & & 60 & & & & & & \\
\hline \multicolumn{10}{|c|}{ Heterogeneity: Chi $^{2}=6.08, \mathrm{df}=3(P=0.11) ; \mathrm{I}^{2}=51 \%$} \\
\hline & & & & & & -1 & $\begin{array}{c}-0.5 \\
\text { Favours } \\
\text { [surgery] }\end{array}$ & 0 & $\begin{array}{c}0.5 \\
\text { Favours } \\
\text { [stent] }\end{array}$ \\
\hline
\end{tabular}

Fig. 6 Technical success: intent-to-treat.

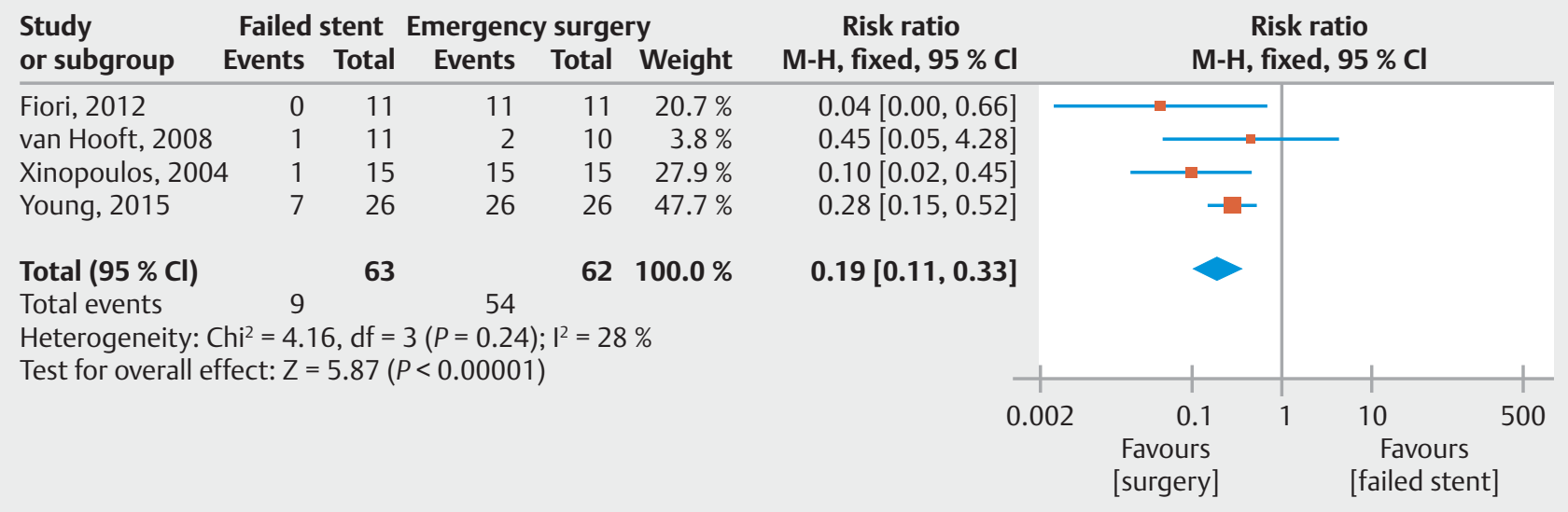

Fig. 7 Stoma formation. 


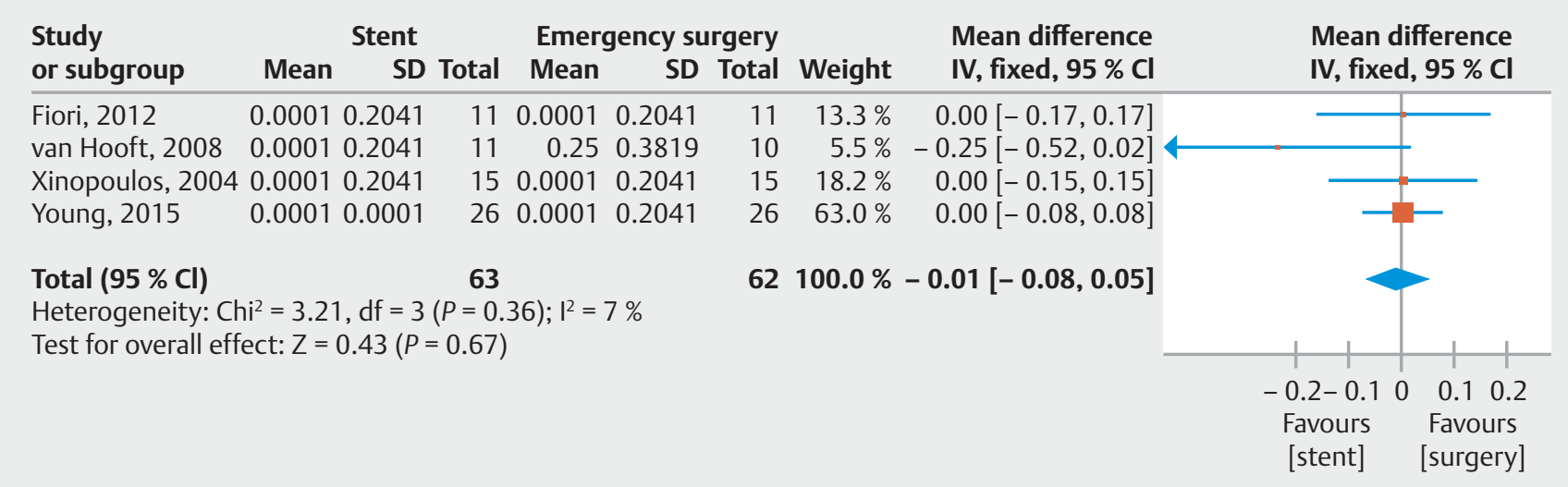

- Fig. 8 Time stay on the intensive care unit.

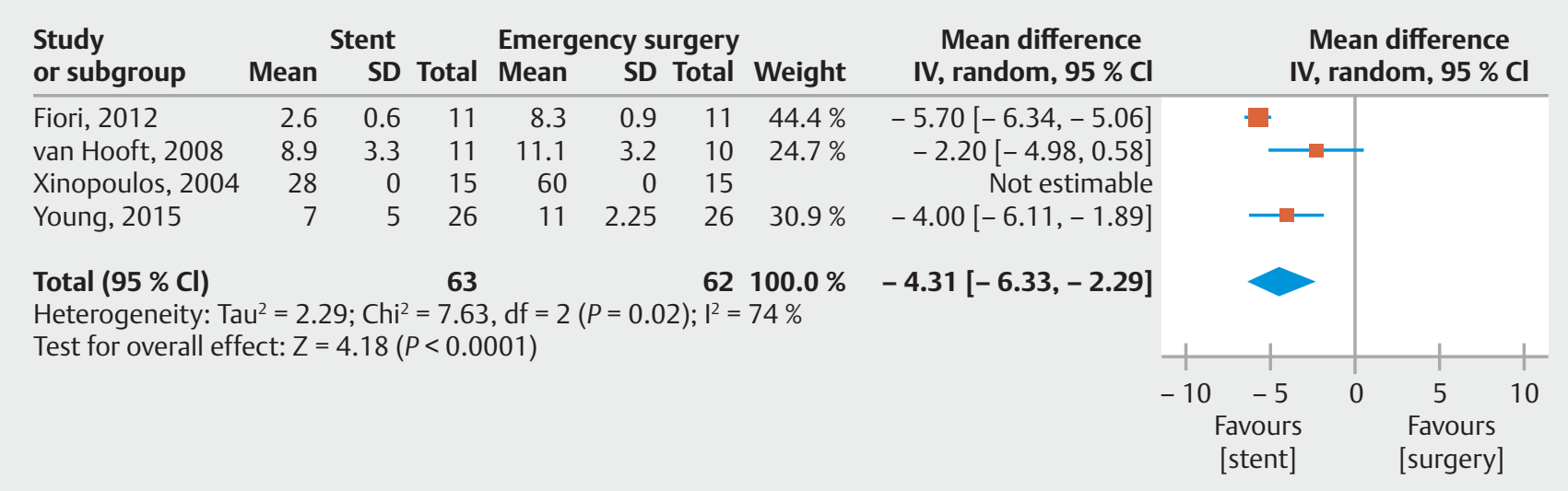

Fig. 9 Hospital stay with outlier.

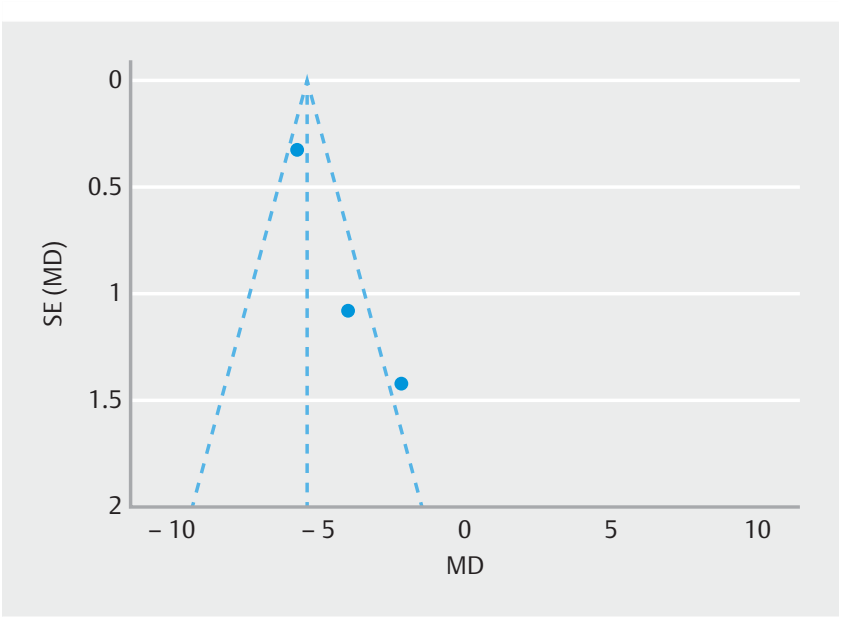

- Fig. 10 Hospital stay: funnel plot.

and 35.5 days in the ES group, with an overall MD of -5.16 (95\% $\mathrm{Cl}:-6.71$ to $-3.61, \mathrm{I}^{2}$ : $\left.56 \%\right)$.

Perforation was the most commonly reported complication in SEMS patients, accounting for $42.8 \%$ of all AEs ( $>$ Fig. 12 ).

\section{Discussion}

For approximately three decades, colonic stents have been used to treat colonic malignancies either as a bridge to surgery or as a palliative measure [27]. The majority of RCTs that focused upon use of SEMS as a bridge to definitive surgery were published in the last decade; however, these studies reported conflicting results, triggering a large debate on the true efficacy of colonic SEMS.

The first RCT that included only palliative patients was published in 2004 [28] and showed promising results for use of SEMS compared to ES as definitive treatment for MCO. In that study, a TS of $93.3 \%$ was reported in the SEMS group, with all patients remaining free of colonic obstruction until their death, which occurred at 6 to 18 weeks of SEMS placement. Stoma was performed in all patients undergoing $E S$, and there was no significant difference between the groups in terms of survival.

The most recent systematic review using RCTs of palliative patients also included data from those in whom SEMS was placed as a bridge to surgery and final treatment [3]; thus these results should be interpreted with caution. The last systematic review regarding SEMS focused on its placement as a bridge to surgery and not as a definitive treatment for palliative patients 


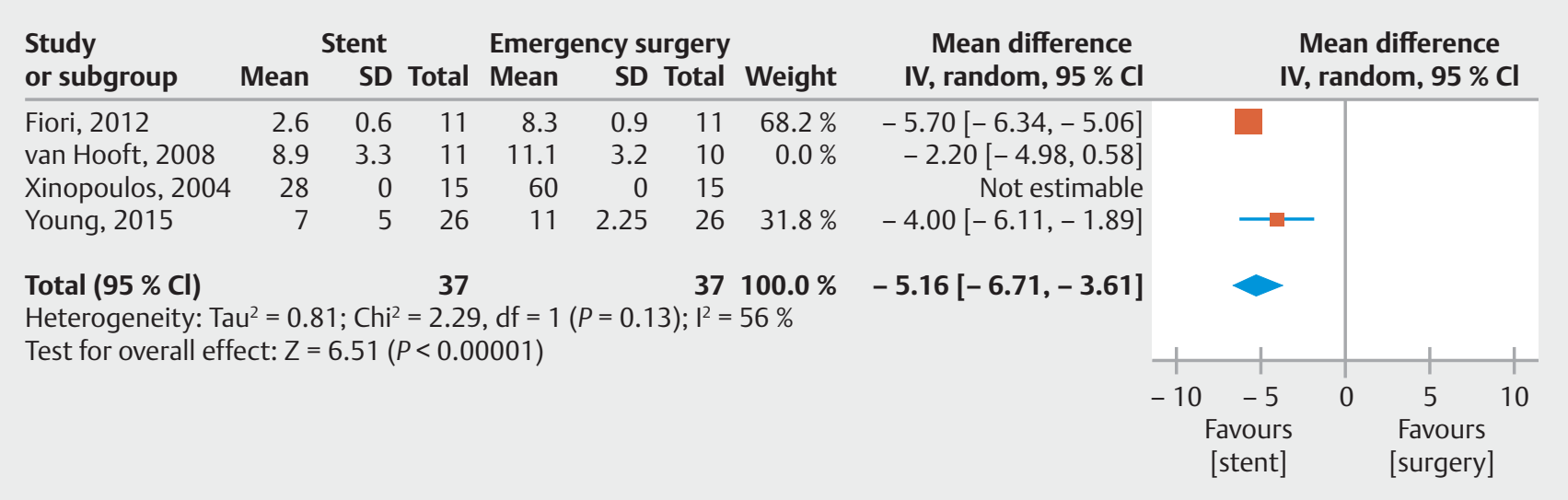

- Fig. 11 Hospital stay without outlier.

\begin{tabular}{llll} 
& Perforation & Migration & Obstruction \\
Fiori[25] $^{[25]}$ & 0 & 0 & 3 \\
van Hoot $^{[26]}$ & 6 & 1 & 2 \\
Young $^{[10]}$ & 0 & 0 & 1 \\
Xinopoulos $^{[28]}$ & 0 & 0 & 1 \\
\hline
\end{tabular}

- Fig. 12 Stent-related complications.

[29]. The current study is the first systematic review that used only RCT (evidence $1 \mathrm{~A}$ ) including palliative patients with CRC.

ES may cause morbidity and may be related to worse healthrelated QOL because an ostomy is the most likely treatment for relieving an obstruction. Conversely, colonic stenting can result in perforation, obstruction and other fatal complications [10, 25, 26, 30].

Because one of the goals for treating patients with advanced neoplasia is to prolong survival and maintain the best QOL possible, SEMS placement may enable patients to maintain a high QOL by avoiding colostomy or other surgical interventions[10].

In 2014, the European Society of Gastrointestinal Endoscopy recommended use of SEMS as the method of choice in patients receiving palliative care on the basis of results of retrospective, case series, and non-comparative studies [2].

Until the emergence of the first RCTs, use of SEMS for treating MCO was thought to reduce morbidity and mortality [31] and to induce less trauma compared with ES. However, this concept was not supported by the RCTs reporting use of SEMS as a bridge to surgery or by their respective meta-analyses.

In this study, we detected no statistical significance between the groups in terms of 30 -day mortality $(6.4 \%$ for the SEMS group and $6.3 \%$ for the ES group). Another meta-analysis [32] demonstrated a significant reduction in mortality in the SEMS group compared with the surgical intervention group. However, in that study, the authors included retrospective studies and non-RCTs, which could have led to selection bias (patients with better prognosis were selected for surgery, whereas those with worse clinical status were selected for stent placement).
Our study showed no significant statistical difference in terms of survival time between the groups, which is in agreement with results of previous meta-analyses [33]. Early complications of stents included perforation, migration, and obstruction, which were observed in $36.5 \%$ of patients. Surgical complications included non-functioning ostomy, suture dehiscence, intestinal volvulus, which were observed in $24.1 \%$ of patients. Contrary to the findings of Takahashi et al., [32] SEMS placement did not reduce risk of early complications as demonstrated by Liang et al. [11].

As expected, the ES group showed favorable results regarding CS but at the cost of a higher risk of colostomy $(86.1 \%$ vs $14.3 \%)$. Despite lower CS rates in the SEMS group, there was no significant increase in the number of early AEs in these patients.

The reported difficulty in the SEMS group was related to performance of the guidewire technique, and the procedure was suspended if there was no success $[10,25,26,28]$.

Although the ES group showed a $13 \%$ superior technique and CS, patients in the SEMS group still had the possibility of surgical intervention if there was a therapeutic failure of both emergency surgery and follow-up[25, 28,34]. Overall, in 9 of the 63 patients randomized to the SEMS group, the technique used had failed; thus, these patients were allocated to the ES group.

Long-term patency of colorectal stents is a matter of concern because obstruction or dislodgment can occur. Late stent dysfunction is reported in up to $19 \%$ of patients undergoing stent placement. However, stent dysfunction is typically treated by tunneling with argon plasma coagulation, laser, or further stenting $[10,25,26,28,34,35]$.

The main limitation of this study was the paucity of data regarding use of SEMS in palliative settings. Only four RCTs on use of SEMS in the palliative scenario were included in this analysis, from which the data were derived. Lack of standardization, such as post-procedure QOL analysis, could not be meta-analyzed owing to the unavailability of a dedicated evaluation questionnaire. 


\section{Conclusion}

Results of this meta-analysis indicate that mortality, mean survival, length of ICU stay, and early complications were similar for both SEMS use and ES. Surgery was associated with higher CS, whereas SEMS corresponded with shorter hospital stay and less permanent stoma. Further studies are required to address whether QOL is affected by any of these treatments.

SEMS may be an alternative for managing patients with unresectable obstructive $C R C$, with the advantage of early hospital discharge and shortened hospitalization time in relation to patients undergoing surgery as well as the main objective in patients receiving palliative care: survival with QOL being able avoid a colostomy.

\section{Competing interests}

None

References

[1] Sagar ], Winslet M. Colorectal stents for the management of malignant colonic obstructions. Cochrane database Syst Rev 2008: CD007378

[2] Van Hooft J, Van Halsema E, Vanbiervliet G et al. European Society of Gastrointestinal Endoscopy Clinical Guideline: Self-expandable metal stents for obstructing colonic and extra-colonic cancer. Endoscopy 2014; 46: 990 - 1002

[3] Shimura T, Joh T. Evidence-based Clinical Management of Acute Malignant Colorectal Obstruction. J Clin Gastroenterol 2016; 50: 273 285

[4] Tilney HS, Lovegrove RE, Purkayastha S et al. Comparison of colonic stenting and open surgery for malignant large bowel obstruction. Surg Endosc Other Interv Tech 2007; 21: 225-233

[5] Khot UP, Lang AW, Murali K et al. Systematic review of the efficacy and safety of colorectal stents. Br J Surg 2002; 89: 1096 - 1102

[6] Ribeiro IB, Gestic MA, Utrini MP et al. Drain amylase levels may indicate gastrojejunostomy leaks after Roux-en-Y gastric bypass. Arq Gastroenterol 2018; 55: 66-72

[7] Hourneaux G, de Moura E, Sakai P et al. Comparative study: auto-expandable metal stent and isoperistaltic esophgogastric bypass]. Acta Gastroenterol Latinoam 2001; 31: 13-22

[8] Gilson K, Paulo S, de Moura E et al. Assesment of placement of the esophageal self-expandable metallic stent in esophageal cancer in patients with or without citorreduction therapy. Arq Bras Cir Dig 2007; 20: $154-160$

[9] Minata M, Bernardo W, Rocha R et al. Stents and surgical interventions in the palliation of gastric outlet obstruction: a systematic review. Endosc Int Open 2016; 4: E1158 -E1170

[10] Young C], De-loyde KJ, Young JM et al. Improving Quality of Life for People with Incurable Large-Bowel Obstruction. Dis Colon Rectum 2015; 58: $838-849$

[11] Liang TW, Sun Y, Wei YC et al. Palliative treatment of malignant colorectal obstruction caused by advanced malignancy: A self-expanding metallic stent or surgery? A system review and meta-analysis Surg Today 2014; 44: $22-33$

[12] Arezzo A, Balague C, Targarona E et al. Colonic stenting as a bridge to surgery versus emergency surgery for malignant colonic obstruction: results of a multicentre randomised controlled trial (ESCO trial). Surg Endosc 2017; 31: $3297-3305$

[13] Oistamo E, Hjern F, Blomqvist L et al. Emergency management with resection versus proximal stoma or stent treatment and planned resection in malignant left-sided colon obstruction. World J Surg Oncol 2016; 14: 232

[14] Sloothaak DAM, van den Berg MW, Dijkgraaf MGW et al. Oncological outcome of malignant colonic obstruction in the Dutch Stent-In 2 trial. Br J Surg 2014; 101: 1751 - 1757

[15] van den Berg MW, Sloothaak DAM, Dijkgraaf MGW et al. Bridge-tosurgery stent placement versus emergency surgery for acute malignant colonic obstruction. Br J Surg 2014; 101: 867 - 873

[16] Ghazal A-HA, El-Shazly WG, Bessa SS et al. Colonic endolumenal stenting devices and elective surgery versus emergency subtotal/total colectomy in the management of malignant obstructed left colon carcinoma. J Gastrointest Surg 2013; 17: 1123-1129

[17] Cheung DY, Kim JY, Hong SP et al. Outcome and safety of self-expandable metallic stents for malignant colon obstruction: a Korean multicenter randomized prospective study. Surg Endosc 2012; 26: $3106-3113$

[18] Ho K-S, Quah H-M, Lim J-F et al. Endoscopic stenting and elective surgery versus emergency surgery for left-sided malignant colonic obstruction: a prospective randomized trial. Int J Colorectal Dis 2012; 27: $355-362$

[19] Alcantara M, Serra-Aracil X, Falco J et al. Prospective, controlled, randomized study of intraoperative colonic lavage versus stent placement in obstructive left-sided colonic cancer. World J Surg 2011; 35: $1904-1910$

[20] Pirlet IA, Slim K, Kwiatkowski F et al. Emergency preoperative stenting versus surgery for acute left-sided malignant colonic obstruction: a multicenter randomized controlled trial. Surg Endosc 2011; 25: $1814-1821$

[21] van Hooft JE, Bemelman WA, Oldenburg B et al. Colonic stenting versus emergency surgery for acute left-sided malignant colonic obstruction: a multicentre randomised trial. Lancet Oncol 2011; 12 : $344-352$

[22] Cui J, Zhang J-L, Wang $S$ et al. A preliminary study of stenting followed by laparoscopic surgery for obstructing left-sided colon cancer. Zhonghua Wei Chang Wai Ke Za Zhi 2011; 14: 40 - 43

[23] Kim JS, Hur H, Min BS et al. Oncologic outcomes of self-expanding metallic stent insertion as a bridge to surgery in the management of left-sided colon cancer obstruction: comparison with nonobstructing elective surgery. World J Surg 2009; 33: 1281-1286

[24] Martinez-Santos C, Lobato RF, Fradejas JM et al. Self-expandable stent before elective surgery vs. emergency surgery for the treatment of malignant colorectal obstructions: Comparison of primary anastomosis and morbidity rates. Dis Colon Rectum 2002; 45: 401-406

[25] Fiori E, Lamazza A, Schillaci A et al. Palliative management for patients with subacute obstruction and stage IV unresectable rectosigmoid cancer: Colostomy versus endoscopic stenting: Final results of a prospective randomized trial. Am J Surg 2012; 204: 321 - 326

[26] van Hooft J, Fockens P, Marinelli A et al. Early closure of a multicenter randomized clinical trial of endoscopic stenting versus surgery for stage IV left-sided colorectal cancer. Endoscopy 2008; 40: 184-191

[27] Dohmoto M. New method; endoscopic implantation of rectal stent in palliative treatment of malignant stenosis. Endosc Dig 1991; 3: $1507-1512$

[28] Xinopoulos D, Dimitroulopoulos D, Theodosopoulos T et al. Stenting or stoma creation for patients with inoperable malignant colonic obstructions? Results of a study and cost-effectiveness analysis Surg Endosc Other Interv Tech 2004; 18: 421-426

[29] Arezzo A, Passera R, Lo Secco G et al. Stent as bridge to surgery for left-sided malignant colonic obstruction reduces adverse events and stoma rate compared with emergency surgery: results of a systematic 
review and meta-analysis of randomized controlled trials. Gastrointest Endosc 2017; 86: 416-426

[30] Frago R, Ramirez E, Millan M et al. Current management of acute malignant large bowel obstruction: a systematic review. Am J Surg 2014; 207: $127-138$

[31] Watt AM, Faragher IG, Griffin TT et al. Self-expanding metallic stents for relieving malignant colorectal obstruction: A systematic review. Ann Surg 2007; 246: $24-30$

[32] Takahashi H, Okabayashi K, Tsuruta M et al. Self-Expanding Metallic Stents Versus Surgical Intervention as Palliative Therapy for Obstructive Colorectal Cancer: A Meta-analysis. World J Surg 2015; 39 : $2037-2044$
[33] Zhao XD, Cai BB, Cao RS et al. Palliative treatment for incurable malignant colorectal obstructions: A meta-analysis. World J Gastroenterol 2013; 19: 5565-5574

[34] Young C], Zahid A. Randomised controlled trial of colonic stent insertion in non-curable large bowel obstruction: a post-hoc cost analysis. Colorectal Dis 2017: doi:10.1111/codi.13951 [Epub ahead of print Nov 1]

[35] Clarke L, Abbott H, Sharma P et al. Impact of restenting for recurrent colonic obstruction due to tumour ingrowth. BJS Open 2018; 1: 202 206

[36] Moher D, Liberati A, Tetzlaff J et al. Preferred reporting items for systematic reviews and meta-analyses: The PRISMA statement. PLoS Medicine; Published: July 21, 2009

\section{CORRECTION}

Ribeiro IB, Bernardo WM, Martins BDC et al. Colonic stent versus emergency surgery as treatment of malignant colonic obstruction in the palliative setting: a systematic review and meta-analysis

Endoscopy International Open 2018; 06: E558-E567. DOI: $10.1055 / a-0591-2883$

In the above mentioned article was a misspelling in three author names. Correct is: Diogo Turiani Hourneaux de Moura, Nelson Tomio Miyajima, Eduardo Guimarães Hourneaux de Moura 